\title{
An Exposure - Risk Assessment for Potentially Toxic Elements in Rice and Bulgur
}

by

\author{
Sait C. Sofuoglu* ${ }^{1,2}$ and Aysun Sofuoglu ${ }^{1}$ \\ Accepted Author Version of the final article published in \\ Environmental Geochemistry and Health
}

The final publication is available at Springer via http://dx.doi.org/10.1007/s10653-017-9954-1

\footnotetext{
${ }^{1}$ Izmir Institute of Technology, Department of Chemical Engineering, Gulbahce, Urla 35430 Izmir, Turkey

${ }^{2}$ Izmir Institute of Technology, Department of Environmental Engineering, Gulbahce, Urla 35430 Izmir, Turkey
}

*Corresponding author, Phone +90-232-750 6648, Fax +90-232-750 6645, e-mail cemilsofuoglu@iyte.edu.tr and saitcemil@iit.edu 


\section{ABSTRACT}

Rice and wheat are rich sources of essential elements. However, they may also accumulate potentially toxic elements (PTE). Bulgur, the popular alternative to rice in the eastern Mediterranean, is produced by processing wheat, during which PTE content may change. This study determined PTE concentrations in rice and bulgur collected from 50 participant households in the City of Izmir, Turkey, estimated ingestion exposure, and associated chronictoxic and carcinogenic human health risks. Comparison of the determined concentrations to the available standard levels and the levels reported in the literature revealed that $\mathrm{Cd}, \mathrm{Co}$, and $\mathrm{Pb}$ in rice might be of concern. The estimated health risks of individual participants supported this result with exceedance of respective threshold or acceptable risk levels at the 95th percentile. Population risk estimates indicated that the proportion with higher than the threshold or acceptable risk is about $10 \%, 24 \%$, and $12 \%$ for $\mathrm{Cd}, \mathrm{Co}$, and $\mathrm{Pb}$ in rice, respectively. Results of this study showed that health risks associated with PTE exposure through bulgur consumption are lower than those of rice, and below the threshold or acceptable risk levels.

Keywords. Toxic elements, ingestion exposure, rice, bulgur, health risks

\section{INTRODUCTION}

Wheat and rice are the two most consumed cereals in the world. They are rich sources of essential elements. However, they are also known to accumulate potentially toxic elements (PTE) when grown on contaminated lands, such as in mining areas (Li et al. 2014a; Robson et al. 2014), around metal recycling and e-waste dismantling facilities (Fu et al. 2013; Li et al. 2014b), and those irrigated with contaminated waters such as from rivers (Si et al. 2015), groundwaters 
Please cite as Sofuoglu SC and Sofuoglu A, 2017, Environ Geochem Health, doi: 10.1007/s 10653-017-9954-1

(Rahman and Hasegawa 2011), and wastewaters (Singh et al. 2010). Because their consumption rates are high, the level of contamination in the grains is the main determinant for ingestion exposure to PTEs, which is very variable depending on factors such as soil and irrigation water characteristics, cultivar, etc.

Rice is one of the main sources of exposure to $\mathrm{As}, \mathrm{Cd}$, and Pb, especially where it is a staple food, i.e., Bangladesh, China, India, etc. (Jorhem et al. 2008; Mondal and Polya 2008; Bergkvist et al. 2010; Norton et al. 2014; Fu et al. 2015), where consumption rates listed by FAOSTAT for 2013 reach up to about half a kilogram per day. Wheat has lower $\mathrm{As}, \mathrm{Cd}$, and $\mathrm{Pb}$ contamination than rice (Adomako et al. 2011; Williams et al. 2007) but the opposite may also be possible under certain conditions (Huang et al. 2008; Shi et al. 2013; Robson et al. 2014). Bulgur is produced from wheat by soaking, cooking, drying, milling, and cracking (Özboy and Köksel 2001), resulting in a quicker cooking product with a longer shelf-life especially in hot-humid environments, and is resistant to mold, mites, and insects (Bayram 2000; Bayram and Öner 2002). Its consumption reaches up to about $100 \mathrm{~g} / \mathrm{d}$ in the eastern Mediterranean (i.e., Iraq, Israel, Lebanon, Syria), while the average is $33 \mathrm{~g} / \mathrm{d}$ in Turkey with wide spatial variation that ranges from $21 \mathrm{~g} / \mathrm{d}$ in the western to $68 \mathrm{~g} / \mathrm{d}$ in the eastern Turkey (Yıldırım et al., 2008). The processing alters the nutritional value of wheat as some vitamin loss occurs (Kadakal et al. 2007), during which PTE content may similarly be reduced or contamination may occur.

Although extensive information on PTE content in wheat and rice from different parts of the world can be found in the literature, there is almost none for bulgur, and it is very limited for rice from Turkey except for As and Cd in rice $(n=25)$ (Gunduz and Akman 2013), Cu and Zn in wheat $(n=10)$ (Arslanbas and Baydan 2013), and that from our previous study, which reported speciated 
arsenic levels in rice and bulgur $(n=50)$, and compared the two in terms of associated health risks (Sofuoglu et al. 2014). The aim of this study was to investigate levels of $\mathrm{Cd}, \mathrm{Co}, \mathrm{Cr}, \mathrm{Cu}, \mathrm{Mn}, \mathrm{Ni}, \mathrm{Pb}$, $\mathrm{Sr}$, and $\mathrm{Zn}$ in rice and bulgur, and to estimate ingestion exposure and associated chronic-toxic and carcinogenic human health risks using the same samples that were collected from participants living in urban Izmir, Turkey, whose exposure-related information were collected by administration of a questionnaire. Both individual and population risk assessments were conducted.

\section{MATERIAL and METHODS}

\subsection{Questionnaire}

Located on the Aegean Sea shore in western Turkey, with a population of about 3.5 million, Izmir is the third largest city in the country. A questionnaire was self-administered for seven days in 2012 by randomly selected participants $(n=50)$ living in the metropole to collect information on the level of daily rice and bulgur consumption, brand and type of the rice and bulgur cooked at home, and demographics including education level, body weight, gender, age, etc.

\subsection{Sample Processing and Analysis}

All participants provided a sample of the rice and bulgur that they cook at home in zip-lock plastic bags. All samples were transferred into 60-mL HDPE bottles when brought to the laboratory, and were kept in the dark and at room temperature. Before use, all plasticware used in the study, e.g., HDPE bottles, pipette tips, and falcon tubes were kept in $20 \%$ nitric acid (Merck) bath for at least 3 hours, rinsed three times with ultra-pure distilled water (Millipore Elix5), and dried in a hood. 
Samples $(0.5 \mathrm{~g})$ were microwave (CEM, MARS X) digested in a solution of $5 \mathrm{ml}$ of $\mathrm{HNO}_{3}(69.5 \%$, Merck, 101799 ACS Reagent Grade for Analysis,), $1 \mathrm{ml}$ of $\mathrm{H}_{2} \mathrm{O}_{2}$ (30\% v/v, Merck 107298 Suprapur), and $1 \mathrm{ml}$ of ultra-pure distilled water for 10 minutes ramping to $150{ }^{\circ} \mathrm{C}$, then for 10 minutes ramping to $180{ }^{\circ} \mathrm{C}$, and for 10 minutes at $180{ }^{\circ} \mathrm{C}$. After digestion, the solution was filtered with a $0.45 \mu \mathrm{m}$ Teflon filter, and completed to $50 \mathrm{ml}$ by ultra-pure distilled water.

Inductively coupled plasma - mass spectrometry (ICP-MS, Agilent 7500ce, Octapole Reaction System) was used for analysis. Calibration was performed with internal standards $\left({ }^{72} \mathrm{Ge}\right.$ and

${ }^{159} \mathrm{~Tb}$ ). Instrumental operating conditions were: RF generator frequency of $27 \mathrm{MHz}$, power output of $1500 \mathrm{~W}$, argon flow rate with plasma $15 \mathrm{l} / \mathrm{min}$, auxiliary $1 \mathrm{l} / \mathrm{min}$, carrier $1 \mathrm{l} / \mathrm{min}$ and, nebulizer 0.08 rps.

\subsection{QA/QC}

Procedural blanks $(n=6)$ were analyzed for blank correction of the sample concentrations, and calculation of Limit of Detection (LOD) as the mean concentration plus three standard deviations, which were: 4.1, 18, 44, 15, 3.3, 6.4, 25, 5.5, $125 \mathrm{ng} / \mathrm{g}$ for $\mathrm{Cd}, \mathrm{Co}, \mathrm{Cr}, \mathrm{Cu}, \mathrm{Mn}, \mathrm{Ni}, \mathrm{Pb}, \mathrm{Sr}$, and $\mathrm{Zn}$, respectively. All reported concentrations in this study are based on wet weight and blank corrected. A standard reference material (Rice Flour, EU-JRC, IRMM-904) was put through the sample processing and ICP-MS analysis. Recoveries, calculated based on the certified concentrations of the SRM for $\mathrm{Cd}, \mathrm{Cu}, \mathrm{Mn}, \mathrm{Pb}$, and $\mathrm{Zn}$ were $96.4 \%, 96.6 \%, 96.5 \%, 91.7 \%$, and $98.4 \%$, respectively. 


\subsection{Exposure - Risk Assessment}

Ingestion exposure was estimated by calculating chronic daily intake using Equation 1:

$C D I=\frac{C \times D I}{B W} \times \frac{E F \times E D}{A T}$

where $C D I$ is the chronic daily intake $(\mu \mathrm{g} / \mathrm{kg}-\mathrm{d}), C$ is the contaminant concentration $(\mu \mathrm{g} / \mathrm{g}) ; D /$ is the average daily intake rate of rice or bulgur $(\mathrm{g} / \mathrm{d})$ estimated as the 7-day average from the questionnaire survey; $B W$ is participant-reported body weight $(\mathrm{kg}) ; E F$ is the exposure frequency $(\mathrm{d} / \mathrm{yr}), E D$ is the exposure duration (yr), $A T$ is the averaging time (day). The second term in the equation is unity for chronic-toxic risk assessment, whereas $E F, E D$, and $A T$ are assumed as 365 $\mathrm{d} / \mathrm{yr}, 70 \mathrm{yr}$, and $70 \times 365 \mathrm{~d}$, respectively, for lifetime carcinogenic risk assessment, for which the second term also becomes unity. Values of the remaining three variables $(C, D I$, and $B W)$ are specific to each study participant so CDI is an estimate of individual ingestion exposure.

The hazard quotient (HQ) was calculated to estimate chronic-toxic risk using Equation-2:

$$
H Q=\frac{C D I}{R f D}
$$

where $R f D$ is the reference dose $(\mu \mathrm{g} / \mathrm{kg}-\mathrm{d})$.

Lifetime carcinogenic risk associated with ingestion exposure was calculated using Equation-3:

$R=C D I \times S F$

where $R$ is the probability of excess lifetime carcinogenic risk (or simply risk), and $S F$ is the slope factor of the contaminant $(\mu \mathrm{g} / \mathrm{kg}-\mathrm{d})^{-1}$. 
RfD values were available for $\mathrm{Cd}, \mathrm{Cr}, \mathrm{Co}, \mathrm{Cu}, \mathrm{Mn}, \mathrm{Ni}, \mathrm{Sr}$, and $\mathrm{Zn}$ as 1.0, 0.0015, 0.3, 40, 140, 20, 600, $300 \mu \mathrm{g} / \mathrm{kg}$-d, respectively (IRIS 2016; RAIS 2016). Conservatively, all $\mathrm{Cr}$ was assumed to be Cr(III). SF value was available for only Pb as $8.5(\mu \mathrm{g} / \mathrm{kg}-\mathrm{d})^{-1}$ (OEHHA 2016).

\subsection{Monte-Carlo Simulation and Statistical Tests}

Population exposure-risk assessment was also carried out using Monte-Carlo simulation (MCS). MCS is a technique that employs statistical sampling techniques in obtaining a probabilistic approximation to the solution of a mathematical equation or a model. Here, the exposure - risk models were simulated with 10000 calculations, producing 10000 estimations that are used to determine their probability distributions. MCS was performed using Crystal Ball (v 4.0e) software. Concentrations were censored for below detection limit (BDL) values to avoid overestimation of exposure and risk. Half the detection limit values were used for censoring because the number of BDL samples were small. Statistical analyses were performed using SPSS (Release 12.0). Kruskal-Wallis test was used for testing differences among $>2$ groups, whereas Mann-Whitney and Kolmogorov-Smirnov tests were used for differences between two groups. A $p$-value that is $<0.05$ was considered to indicate a significant difference. Factor analysis was conducted to infer the source apportionment of contamination. Varimax rotated principal component analysis was used. Eigen values of $>1$ and loadings of $>0.45$ were regarded as significant for interpretation of factors.

\section{RESULTS and DISCUSSION}

Results of the questionnaire survey $(n=50)$ were presented in our previous study (Sofuoglu et al. 2014). Briefly, participant age ranged from 14 to 75 years with an average of 33.5 years. The 
Please cite as Sofuoglu SC and Sofuoglu A, 2017, Environ Geochem Health, doi: 10.1007/s 10653-017-9954-1

mean participant body weight was $66 \mathrm{~kg}$, which ranged from 46 to $95 \mathrm{~kg}$. The majority of the participant households preferred medium-grain rice. Before cooking, the rice was kept in hot water that was discarded afterwards. Mihucz et al. (2010) reported that this practice reduces rice contaminant concentrations by $10 \%-33 \%$ for $\mathrm{Cu}, \mathrm{Mn}$, and $\mathrm{Zn}, 45 \%-66 \%$ for $\mathrm{Ni}$, and $60 \%-$ $90 \%$ for Ti. The mean and median values, and ranges of daily consumption rates were $38 \mathrm{~g} / \mathrm{d}, 35$ $\mathrm{g} / \mathrm{d}$, and $5-75 \mathrm{~g} / \mathrm{d}$ for rice, and $22 \mathrm{~g} / \mathrm{d}, 22 \mathrm{~g} / \mathrm{d}$, and $0-113 \mathrm{~g} / \mathrm{d}$ for bulgur, respectively.

\subsection{PTE Concentrations}

The proportion of BDL samples was $\leq 10 \%$ for all PTEs in rice except for $\mathrm{Ni}(50 \%)$, whereas it was $14 \%, 18 \%, 20 \%$, and $60 \%$ for $\mathrm{Cd}, \mathrm{Co}, \mathrm{Pb}$, and $\mathrm{Cr}$ in bulgur, respectively. In addition to the concentrations of $\mathrm{Ni}$ in rice and $\mathrm{Cr}$ in bulgur being largely $\mathrm{BDL}$, levels of $\mathrm{Ni}$ in bulgur and $\mathrm{Cr}$ in rice were low, which translated into negligible risk levels. Therefore, those two elements have not been studied further. Figure 1 shows the box-plots for the measured PTE concentrations $(\mu \mathrm{g} / \mathrm{g})$ in rice and bulgur, four of which with relatively low concentrations are shown in a zoom-in graph in $\mathrm{ng} / \mathrm{g}$. Cd, Co, $\mathrm{Pb}$, and $\mathrm{Sr}$ were at lower concentrations (with $<1 \mu \mathrm{g} / \mathrm{g}$ 95th percentile values except for Sr in bulgur at about 95th percentile level of $10 \mu \mathrm{g} / \mathrm{g}$ ) compared to $\mathrm{Cu}, \mathrm{Mn}$, and $\mathrm{Zn}$.

$\mathrm{Cd}, \mathrm{Co}$, and $\mathrm{Pb}$ concentrations were significantly higher in rice, while $\mathrm{Sr}, \mathrm{Cu}, \mathrm{Mn}$, and $\mathrm{Zn}$ were at significantly higher levels in bulgur. Maximum Contaminant Levels (MCLs) have been specified in Turkish (Official Gazette No 28157, 29/12/2011) and European Union (Commission Regulation No 1881/2006, 19/12/2006) regulations as $0.2 \mu \mathrm{g} / \mathrm{g}$ wet weight for $\mathrm{Cd}$ and $\mathrm{Pb}$. All measured concentrations, except for $\mathrm{Cd}$ in 17 rice samples, complied with this standard level. Cd levels in eight of the 17 samples (16\%) had considerably high concentrations; three with $>1 \mu \mathrm{g} / \mathrm{g}$ and five 
Please cite as Sofuoglu SC and Sofuoglu A, 2017, Environ Geochem Health, doi: 10.1007/s 10653-017-9954-1

between 0.5 and $1 \mu \mathrm{g} / \mathrm{g}$. Similarly high $\mathrm{Cd}$ concentrations in rice were reported from China (Fu et al. 2015; Fangmin et al. 2006; Li et al. 2012; Zhuang et al. 2009; Huang et al. 2013), reaching 6.99 $\mu \mathrm{g} / \mathrm{g}$ in rice grown in contaminated areas (Liu et al. 2005). The only available reports from Turkey were the mean Cd concentration as $0.031 \mu \mathrm{g} / \mathrm{g}$ (Gunduz and Akman 2013), and the mean Cu and Zn concentrations of $4.96 \mu \mathrm{g} / \mathrm{g}$ and $26.0 \mu \mathrm{g} / \mathrm{g}$, respectively (Arslanbas and Baydan 2013), which are higher than those of $\mathrm{Cu}$ and $\mathrm{Zn}$ measured in this study as $1.71 \mu \mathrm{g} / \mathrm{g}$ and $12.0 \mu \mathrm{g} / \mathrm{g}$, respectively, but lower than that of $\mathrm{Cd}$ as $0.23 \mu \mathrm{g} / \mathrm{g}$. However, distribution of $\mathrm{Cd}$ concentrations is very skewed (2.33) due to three samples with very high ( $>1 \mu \mathrm{g} / \mathrm{g})$ and seven moderately high $(0.4-1.0 \mu \mathrm{g} / \mathrm{g})$ concentrations. Therefore, the median is a better measure of central tendency for $\mathrm{Cd}(0.012 \mu \mathrm{g} / \mathrm{g})$, and is lower than the mean reported by Gunduz and Akman (2013). Nevertheless, the median $\mathrm{Cd}$ concentration in rice measured in this study is similar to the "global mean" concentration $(0.020 \mu \mathrm{g} / \mathrm{g})$ reported by Adomako et al. (2011). Skewness of the remaining PTEs was low in rice $(\leq 0.68)$ except for $\mathrm{Pb}(1.69)$ which still is $<2$. Distributions of only $\mathrm{Cd}$ and $\mathrm{Pb}$ were also skewed for bulgur (2.1 and 4.1, respectively) while the skewness for the remaining PTEs were low $(\leq 1.1)$. The median and mean PTE concentrations and the reported "global mean values" are listed in Table 1. All measured Pb concentrations both in rice and bulgur with 95th percentiles of just above and below $0.010 \mu \mathrm{g} / \mathrm{g}$, respectively, were below the MCL of $0.2 \mu \mathrm{g} / \mathrm{g}$. The median values for both rice and for bulgur are similar to the "global mean" concentration for rice. The "global mean" concentrations reported as 10 and $38 \mu \mathrm{g} / \mathrm{g}$ in rice and wheat for $\mathrm{Mn}$, respectively, are higher than the respective median levels measured in this study. While the median Co concentration in rice is higher than the "global mean" concentration, it is similar for bulgur. The comparison is vice-versa for $\mathrm{Zn}$, as the measured median for rice is similar to the 
"global mean", while the median for bulgur is higher than the "global mean" for wheat. As a result, $\mathrm{Cd}, \mathrm{Co}$ and $\mathrm{Pb}$ in rice can be put forward as the PTEs that might be of concern based on the comparisons to the available MCLs and the levels reported in the literature.

There were 11 different brands of rice consumed in households of the participants, however, three brands (two generic and one main brand) and no-name (NN) rice constituted the majority (66\%). Kruskal Wallis test did not indicate a difference in PTE median concentrations of the four groups of samples $(p>0.34)$. Rice type, however, was found to be a significant factor for $\mathrm{Cd}$ content as Osmancık rice, preferred by $26 \%$ of the participants, with a median concentration of $360 \mathrm{ng} / \mathrm{g}$ is higher than that $(7 \mathrm{ng} / \mathrm{g})$ of Baldo rice $(p=0.029)$, which is preferred by $66 \%$. There were 13 different brands of bulgur consumed in households of the participants, however, two generic brands and no-name bulgur were preferred by more than half of the households (54\%). Kruskal Wallis test did not indicate a difference in median PTE concentrations of the three groups of samples $(p>0.28)$ except for $\mathrm{Pb}(p=0.12)$ that had a higher concentration $(21 \mathrm{ng} / \mathrm{g})$ in $\mathrm{NN}$ samples than the two preferred brands with medians of $8 \mathrm{ng} / \mathrm{g}(p=0.087)$ and $10 \mathrm{ng} / \mathrm{g}(p=0.090)$ according to Mann-Whitney test results.

\subsection{Individual Exposure Assessment}

Exposure to PTEs via ingestion of rice and bulgur was estimated for the 50 study participants by using the 7-day average rice and bulgur consumption rates and body weights obtained from the questionnaire survey, and the measured concentrations. Table 2 presents descriptive statistics for the estimated individual exposures. The exposures are compared to tolerable intake levels by the Joint Food and Agriculture Organization of the United Nations / WHO Expert Committee on 
Please cite as Sofuoglu SC and Sofuoglu A, 2017, Environ Geochem Health, doi: 10.1007/s 10653-017-9954-1

Food Additives (JECFA). A provisional tolerable monthly intake (PTMI) of $25 \mu \mathrm{g} / \mathrm{kg}$-month (JEFCA 2013) for Cd and provisional maximum tolerable daily intake (PMTDI) of $500 \mu \mathrm{g} / \mathrm{kg}$ - $\mathrm{d}$ for $\mathrm{Cu}$ and 300-1000 $\mu \mathrm{g} / \mathrm{kg}$-d for Zn (JEFCA 1982) were available for comparison. A provisional tolerable weekly intake (PTWI) of $25 \mu \mathrm{g} / \mathrm{kg}$-d for Pb was withdrawn because it was found not to be possible to establish a new PTWI that would be considered health protective (JEFCA 2011). Figure 2 shows the ratio of median and 95th percentile exposures to the tolerable intake levels (the midpoint of the range was taken for $\mathrm{Zn}$ ). Even the maximum individual exposure is $1.4 \%$ and $2.8 \%$ of the PMTDI of Cu for rice and bulgur, respectively. The ratio of 95th percentile individual exposure to PMTDI for Zn are 15-4.5\% for rice and 10-3.1\% for bulgur. Percentages are much higher for $\mathrm{Cd}$ at median, mean, and 95 th percentile exposure values at $2.4 \%, 44 \%$, and $185 \%$, respectively, for rice, but not as high for bulgur at $0.6 \%, 1.1 \%$, and $2.4 \%$, respectively. As a result, it can be inferred that exposure to $\mathrm{Cd}$ and $\mathrm{Pb}$ through rice consumption is considerable.

Estimated average exposures via rice consumption were reported for $\mathrm{Cd}, \mathrm{Cu}$, and $\mathrm{Pb}$ from Fuzhou, China as 0.6, 12.4, and $0.4 \mu \mathrm{g} / \mathrm{kg}$-d ( Fu et al. 2015); for Cd and Pb from Zhejiang, China as 0.23 and $0.37 \mu \mathrm{g} / \mathrm{kg}$-d (Huang et al. 2013); for $\mathrm{Cd}, \mathrm{Cu}, \mathrm{Pb}$, and $\mathrm{Zn}$ from Changshu, China as 0.1, 26.7, 1.2, and $133 \mu \mathrm{g} / \mathrm{kg}$-d (Hang et al. 2009); for Cd, Co, Cu, Mn, and Zn from Brazil as 2.4, 3.1, 200, 1900, and $1600 \mu \mathrm{g} / \mathrm{kg}$-d (Batista et al. 2010); for Cd and Pb as ranges of median values of different age groups from China as 0.10 to 0.23 and 0.33 to $0.78 \mu \mathrm{g} / \mathrm{kg}$-d (Qian et al. 2010); for Cd and Pb from Kuwait as 0.03 and $0.018 \mu \mathrm{g} / \mathrm{kg}$-d (Jallad 2015); for Cd (as median value) from unpolluted and polluted areas of rural China as 0.53 and $1.83 \mu \mathrm{g} / \mathrm{kg}$-d (Zhu et al. 2016). Estimated average exposures via wheat consumption were reported for $\mathrm{Cd}, \mathrm{Cu}, \mathrm{Pb}$, and $\mathrm{Zn}$ from Tianjin sewage irrigation area, China, as $0.12,6.33,0.30$, and $58.2 \mu \mathrm{g} / \mathrm{kg}-\mathrm{d}$ (Zeng et al. 2015). 
Please cite as Sofuoglu SC and Sofuoglu A, 2017, Environ Geochem Health, doi: 10.1007/s 10653-017-9954-1

There are other studies that estimated risks associated with PTEs in wheat but these did not report exposure levels (Bermudez et al. 2011; Huang et al. 2008; Yeganeh et al. 2012), which will be discussed in the next section.

\subsection{Individual Risk Assessment}

Health risks associated with PTE ingestion by consumption of rice and bulgur were calculated for the 50 participants. Chronic-toxic risks could be estimated for $\mathrm{Cd}, \mathrm{Co}, \mathrm{Cu}, \mathrm{Mn}, \mathrm{Sr}$, and $\mathrm{Zn}$, while carcinogenic risk could be estimated for only $\mathrm{Pb}$, due to availability of risk factors. The risks are evaluated by comparing with threshold HQ levels of 0.1 and 1.0 for chronic-toxic effects, and the acceptable risk of $1.0 \times 10^{-6}$ for carcinogenic effects. Descriptive statistics for the estimated risks are presented in Table 3, in which values exceeding the specified values are highlighted. No median or mean HQ value exceeded the threshold of 1.0 for rice or for bulgur. However, the median and mean $\mathrm{HQ}$ for $\mathrm{Co}$ and the mean $\mathrm{HQ}$ for $\mathrm{Cd}$ in rice are $>0.1$. HQ levels at 95th percentile are $>1.0$ for $\mathrm{Cd}$ and Co in rice indicating chronic-toxic risks associated with consumption of rice, which needs to be investigated further. All others at even 95th percentile or maximum levels are between 0.1 and 1.0, which indicates probable concern for people who consume No-Name or generic brands with consumption rates higher than those encountered in this study. No safe level can be attributed for Pb (JEFCA 2011); however, carcinogenic risks could be estimated using the risk factor published by California EPA (OEHHA 2016). The estimated risks are below the acceptable level at the median and mean levels for both rice and bulgur. Nonetheless, it exceeds the acceptable level at the 95th percentile for rice, while it is about the acceptable level even at the maximum for bulgur. 
Please cite as Sofuoglu SC and Sofuoglu A, 2017, Environ Geochem Health, doi: 10.1007/s 10653-017-9954-1

Chronic-toxic risks associated with PTE exposure by rice intake were reported by five out of the seven studies that were cited for estimated exposures (Section 3.2), all of which were conducted in China ( Fu et al. 2015; Hang et al. 2009; Huang et al. 2013; Qian et al. 2010). Average risks were reported for $\mathrm{Cd}, \mathrm{Cu}, \mathrm{Pb}$, and $\mathrm{Zn}$, and all were between 0.1 and 1.0. Reports of chronic-toxic risk for wheat included studies from Argentina and Iran (Bermudez et al. 2011; Yeganeh et al. 2012) in addition to those from China (Huang et al. 2008; Zeng et al. 2015). The risk levels reported from China for $\mathrm{Cd}, \mathrm{Cu}, \mathrm{Pb}$, and $\mathrm{Zn}$ were either $<0.1$ or between 0.1 and 1.0. Likewise, risk levels for $\mathrm{Cd}, \mathrm{Co}, \mathrm{Cu}, \mathrm{Pb}$, and $\mathrm{Zn}$ reported from Argentina and Iran were either $<0.1$ or $0.1-1.0$, whereas the risks for $\mathrm{Mn}$ in the Argentine study, and for $\mathrm{Pb}$ in the Iranian study exceeded the threshold of 1.0. The carcinogenic risks estimated in the study conducted in Iran were between $10^{-6}$ and $10^{-5}$. In conclusion, both chronic-toxic and carcinogenic risk levels reported in the literature for rice are in similar ranges to those determined in this study. On the other hand, the above-mentioned risk levels reported for wheat consumption are generally higher than those determined for bulgur in this study, specifically for $\mathrm{Cu}, \mathrm{Mn}$, and $\mathrm{Zn}$, which might indicate that processing of wheat results in lower PTE content in bulgur. This speculation is supported by higher PTE levels in wheat than bulgur (1.7 folds for Cu and Zn, and 3.1 folds for Mn; see Section 3.1, Table 1).

There were significant differences in chronic-toxic risks associated with bulgur consumption among the education levels of primary school - high school - undergraduate, but the differences were not significant for $\mathrm{Pb}$ carcinogenic risk. Two-group comparisons showed primary school graduates have lower HQs than both high school and university graduates with a Mann-Whitney test (confirmed with Kolmogorov-Smirnov (K-S) test for $\mathrm{Cd}, \mathrm{Cu}, \mathrm{Mn}$, and $\mathrm{Zn}$, but not for $\mathrm{Sr}$ 
between primary and high school). Differences may be due to higher level of consumption by graduates of high school or higher (medians of 25 vs. $59 \mathrm{~g} / \mathrm{d}$ ), between which the difference was not significant. The differences in both consumption and risks between genders were not significant. The differences in risks were also not significant among groups of different family sizes that ranged from 1 to 6 with majority between 2 and 5 . Factor analysis showed that PTEs can be grouped under three factors as (1) $\mathrm{Cu}, \mathrm{Mn}$, and $\mathrm{Zn},(2) \mathrm{Cd}, \mathrm{Co}$, and (3) Pb; indicating PTE contamination might have occurred from three sources: the first probably being soil, and the second and the third probably being two different anthropogenic sources. If previously published As concentrations (Sofuoglu et al. 2014) are included, four factors were extracted: (1) $\mathrm{Cu}, \mathrm{Mn}$, and $\mathrm{Zn}$, (2) $\mathrm{Cd}, \mathrm{Co}$, and $\mathrm{As}$, (3) Sr, and (4) Pb. The inclusion of As results in the addition of As into the $\mathrm{Cd}$ and $\mathrm{Co}$ anthropogenic source, with $\mathrm{Sr}$ indicating another source which might be of both crustal and anthropogenic origins.

Demographic variables, such as education level, gender, age, etc., may affect consumption rate, preferences for grain type, brand, etc., which determine the resulting exposure-risk through the level of contamination in the grains. For rice, the differences in risk levels were significant among primary school - high school - university graduates except for Cd-HQ. Two-group comparisons showed primary school graduates have lower risks compared to high school for all PTEs, probably due to significant difference in consumption rate (75 vs. $125 \mathrm{~g} / \mathrm{d})$, all of which were confirmed with a K-S test, and they have lower risks compared to undergraduates for $\mathrm{Cu}$ and $\mathrm{Zn}$ (but not confirmed with the K-S test). The differences were significant for $\mathrm{Sr}$ and $\mathrm{Pb}$ between high school and undergraduates (confirmed with a K-S test) but probably not due to the difference in consumption ( $p>0.05$ with $\mathrm{M}-\mathrm{W}$ test and confirmed with the $\mathrm{K}-\mathrm{S}$ test) although it 
Please cite as Sofuoglu SC and Sofuoglu A, 2017, Environ Geochem Health, doi: 10.1007/s 10653-017-9954-1

was large $(125 \mathrm{~g} / \mathrm{d}$ vs. $81 \mathrm{~g} / \mathrm{d})$. The differences in consumption and risks were not significant between genders and among the groups of different family sizes. Factor analysis showed that PTEs can be grouped under four factors as (1) $\mathrm{Cu}$ and $\mathrm{Mn},(2) \mathrm{Pb}$ and $\mathrm{Zn},(3) \mathrm{Cd}$ and $\mathrm{Co}$, and (4) Sr, indicating contamination might have occurred from four sources: (1) probably is soil, (2) and (3) are two different anthropogenic sources, and (4) is a source which might be of both crustal and anthropogenic origins. If As is included, again four factors were obtained: (1) Cu and Mn, (2) As, (3) Pb and $\mathrm{Cd}$, and (4) Sr. The inclusion of As resulted in a specific source for As that may be contaminated soils other than the soil source represented by $\mathrm{Cu}$ and $\mathrm{Mn}$, (3) being anthropogenic contamination with $\mathrm{Pb}$ and $\mathrm{Cd}$, and (4) being a source which might be of both crustal and anthropogenic origins.

\subsection{Population Risk Assessment}

Figure 3 shows the simulated population risk as frequency histograms, which also presents the fitted distributions and their parameter values. The fitted distribution for the input variables to the exposure-risk model are provided in the Supporting Information. For bulgur, the mean and median chronic-toxic risks were less than the lower threshold value $(\mathrm{HQ}<0.1)$ for all investigated PTEs, and the mean and median carcinogenic risks estimated for Pb were lower than the acceptable risk $\left(10^{-6}\right)$. The $95^{\text {th }}$ percentile chronic-toxic risks did not exceed the threshold of 1.0 with the highest of 0.19 for $\mathrm{Mn}$. The $95^{\text {th }}$ percentile for $\mathrm{Pb}$ carcinogenic risk is below the acceptable risk level. The median and mean chronic-toxic risk levels were also $<0.1$ for PTEs in rice except for $\mathrm{Cd}$ (0.05 and 0.26 , respectively) and Co (0.63 and 0.72 , respectively) while those of $\mathrm{Pb}$ carcinogenic risk were below the acceptable risk level. The $95^{\text {th }}$ percentile levels of $\mathrm{Cd}$ and $\mathrm{Co}$ chronic-toxic risk, and $\mathrm{Pb}$ carcinogenic risk were in exceedance of the threshold of $\mathrm{HQ}=1.0$ and 
acceptable risk of one in a million, respectively. The estimated percentage of population with higher than the threshold or acceptable risk is about $10 \%, 24 \%$, and $12 \%$ for $\mathrm{Cd}, \mathrm{Co}$, and $\mathrm{Pb}$, respectively.

An analysis was conducted using the bootstrapping method to estimate uncertainty in the population risk due to the statistical sampling in simulation. Results of uncertainty analysis are listed in Table 4 as $5^{\text {th }}$ to $95^{\text {th }}$ percentile range for the $50^{\text {th }}$ and $95^{\text {th }}$ percentile risks. In addition, Quartile Coefficient of Dispersion (QCD) was calculated to put the estimated uncertainty into perspective. QCD is the non-parametric analogous to the parametric Coefficient of Variation, which is calculated by dividing the interquartile range by the median value. Here we used the $5^{\text {th }}$ to $95^{\text {th }}$ percentile range instead of the interquartile range to enhance the uncertainty estimations. The calculated QCD values were $<15 \%$ except for $\mathrm{Cd}$ and $\mathrm{Pb}$, which ranged from $38 \%$ to $95 \%$ and $17 \%$ to $38 \%$, respectively, indicating low uncertainty for $\mathrm{Co}, \mathrm{Cu}, \mathrm{Mn}, \mathrm{Sr}$, and $\mathrm{Zn}$, moderate uncertainty for $\mathrm{Pb}$, and high uncertainty for $\mathrm{Cd}$ due to the statistical sampling process, which is probably related to the skewness of their distribution (see Fig. 3).

\section{CONCLUSION}

The estimations obtained in this study indicate that chronic-toxic risks for $\mathrm{Cd}$ and $\mathrm{Co}$, and carcinogenic risks for $\mathrm{Pb}$ associated with rice consumption exceeded respective threshold and acceptable risk levels for considerable proportions of urban Izmir population, whereas all were below those for bulgur consumption. Although $\mathrm{Cu}, \mathrm{Mn}$, and $\mathrm{Zn}$ levels were higher in bulgur than rice, all associated chronic-toxic risks were below the threshold level. Hence, based on the scope of this study, bulgur is a healthier food than rice. 


\section{ACKNOWLEDGEMENTS}

We thank Hilal Güzelkaya, Özlem Akgül, and Pınar Kavcar for collection and extraction of the samples. Environmental Research Center at Izmir Institute of Technology (IzTech) is acknowledged for microwave digestion and ICP-MS analysis. We also thank IzTech School of Engineering for providing consumables for digestion procedure.

\section{REFERENCES}

Adomako, E. E., Williams, P. N., Deacon, C., \& Meharg, A. A. (2011). Inorganic arsenic and trace elements in Ghanaian grain staples. Environmental Pollution, 159(10), 2435-2442, doi:10.1016/j.envpol.2011.06.031.

Arslanbas, E., \& Baydan, E. (2013). Metal levels in organically and conventionally produced animal and vegetable products in Turkey. Food Additives \& Contaminants Part B-Surveillance, 6(2), 130-133, doi:10.1080/19393210.2013.764931.

Batista, B. L., Souza, V. C. D., Da Silva, F. G., \& Barbosa, F. (2010). Survey of 13 trace elements of toxic and nutritional significance in rice from Brazil and exposure assessment. Food Additives \& Contaminants Part B-Surveillance, 3(4), 253-262, doi:10.1080/19393210.2010.516024.

Bayram, M. (2000). Bulgur around the world. Cereal Foods World, 45(2), 80-82.

Bayram, M., \& Öner, M. D. (2002). The new old wheat. World Grain, November, 51-53.

Bergkvist, C., Kippler, M., Hamadani, J. D., Grander, M., Tofail, F., Berglund, M., et al. (2010). Assessment of early-life lead exposure in rural Bangladesh. Environmental Research, 110(7), 718-724, doi:10.1016/j.envres.2010.07.004.

Bermudez, G. M. A., Jasan, R., Pla, R., \& Luisa Pignata, M. (2011). Heavy metal and trace element concentrations in wheat grains: Assessment of potential non-carcinogenic health hazard through their consumption. Journal of Hazardous Materials, 193, 264-271, doi:10.1016/j.jhazmat.2011.07.058.

Fangmin, C., Ningchun, Z., Haiming, X., Yi, L., Wenfang, Z., Zhiwei, Z., et al. (2006). Cadmium and lead contamination in japonica rice grains and its variation among the different locations in southeast China. Science of the Total Environment, 359(1-3), 156-166, doi:10.1016/j.scitotenv.2005.05.005.

Fu, J., Zhang, A., Wang, T., Qu, G., Shao, J., Yuan, B., et al. (2013). Influence of E-Waste Dismantling and Its Regulations: Temporal Trend, Spatial Distribution of Heavy Metals in Rice Grains, and Its Potential Health Risk. Environmental Science \& Technology, 47(13), 7437-7445, doi:10.1021/es304903b.

Fu, Q.-L., Li, L., Achal, V., Jiao, A.-Y., \& Liu, Y. (2015). Concentrations of Heavy Metals and Arsenic in Market Rice Grain and Their Potential Health Risks to the Population of Fuzhou, China. Human and Ecological Risk Assessment, 21(1), 117-128, doi:10.1080/10807039.2014.884398. 
Gunduz, S., \& Akman, S. (2013). Investigation of Arsenic and Cadmium Contents in Rice Samples in Turkey by Electrothermal Atomic Absorption Spectrometry. Food Analytical Methods, 6(6), 1693-1696, doi:10.1007/s12161-013-9588-6.

Hang, X. S., Wang, H. Y., Zhou, J. M., Ma, C. L., Du, C. W., \& Chen, X. Q. (2009). Risk assessment of potentially toxic element pollution in soils and rice (Oryza sativa) in a typical area of the Yangtze River Delta. Environmental Pollution, 157(8-9), 2542-2549, doi:10.1016/j.envpol.2009.03.002.

Huang, M., Zhou, S., Sun, B., \& Zhao, Q. (2008). Heavy metals in wheat grain: Assessment of potential health risk for inhabitants in Kunshan, China. Science of the Total Environment, 405(1-3), 54-61, doi:10.1016/j.scitotenv.2008.07.004.

Huang, Z., Pan, X.-D., Wu, P.-G., Han, J.-L., \& Chen, Q. (2013). Health Risk Assessment of Heavy Metals in Rice to the Population in Zhejiang, China. PLoS One, 8(9), 10.1371/journal.pone.0075007, doi:10.1371/journal.pone.0075007.

IRIS (2016). Integrated Risk Information System. www.epa.gov/iris Accessed April 2016.

Jallad, K. (2015). Heavy metal exposure from ingesting rice and its related potential hazardous health risks to humans. Environmental Science and Pollution Research, 22(20), 1544915458, doi:10.1007/s11356-015-4753-7.

JEFCA (1982). Evaluation of certain food additives and contaminants, Twenty-sixth meeting of the Joint FAO/WHO Expert Committee on Food Additives. WHO Food Additives Series. Geneva.

JEFCA (2011). Safety evaluation of certain food additives and contaminants, Seventy-third meeting of the Joint FAO/WHO Expert Committee on Food Additives WHO Food Additives Series. Geneva.

JEFCA (2013). Safety evaluation of certain food additives and contaminants, Seventy-seventh meeting of the Joint FAO/WHO Expert Committee on Food Additives WHO Food Additives Series. Geneva: World Health Organization.

Jorhem, L., Åstrand, C., Sundström, B., Baxter, M., Stokes, P., Lewis, J., et al. (2008). Elements in rice from the Swedish market: 1. Cadmium, lead and arsenic (total and inorganic). Food Additives \& Contaminants: Part A, 25(3), 284-292, doi:10.1080/02652030701474219.

Kadakal, Ç., Ekinci, R., \& Yapar, A. (2007). The Effect of Cooking and Drying on the Water-Soluble Vitamins Content of Bulgur. Food Science and Technology International, 13(5), 349-354, doi:10.1177/1082013207085688.

Li, Q., Chen, Y., Fu, H., Cui, Z., Shi, L., Wang, L., et al. (2012). Health risk of heavy metals in food crops grown on reclaimed tidal flat soil in the Pearl River Estuary, China. Journal of Hazardous Materials, 227-228, 148-154, doi:10.1016/j.jhazmat.2012.05.023.

Li, W. C., Ouyang, Y., \& Ye, Z. H. (2014a). Accumulation of mercury and cadmium in rice from paddy soil near a mercury mine. Environmental Toxicology and Chemistry, 33(11), 24382447, doi:10.1002/etc.2706.

Li, W., Xu, B., Song, Q., Liu, X., Xu, J., \& Brookes, P. C. (2014b). The identification of 'hotspots' of heavy metal pollution in soil-rice systems at a regional scale in eastern China. Science of the Total Environment, 472, 407-420, doi:10.1016/j.scitotenv.2013.11.046.

Liu, H., Probst, A., \& Liao, B. (2005). Metal contamination of soils and crops affected by the Chenzhou lead/zinc mine spill (Hunan, China). Science of the Total Environment, 339(1-3), 153-166, doi:10.1016/j.scitotenv.2004.07.030. 
Mihucz, V. G., Silversmit, G., Szaloki, I., de Samber, B., Schoonjans, T., Tatar, E., et al. (2010). Removal of some elements from washed and cooked rice studied by inductively coupled plasma mass spectrometry and synchrotron based confocal micro-X-ray fluorescence. Food Chemistry, 121(1), 290-297, doi:10.1016/j.foodchem.2009.11.090.

Mondal, D., \& Polya, D. A. (2008). Rice is a major exposure route for arsenic in Chakdaha block, Nadia district, West Bengal, India: A probabilistic risk assessment. Applied Geochemistry, 23(11), 2987-2998, doi:http://dx.doi.org/10.1016/j.apgeochem.2008.06.025.

Norton, G. J., Williams, P. N., Adomako, E. E., Price, A. H., Zhu, Y., Zhao, F.-J., et al. (2014). Lead in rice: Analysis of baseline lead levels in market and field collected rice grains. Science of the Total Environment, 485, 428-434, doi:10.1016/j.scitotenv.2014.03.090.

OEHHA (2016). OEHHA Chemical Database. California Environmental Protection Agency, Office of Environmental Health Hazard Assessment.

Özboy, Ö., \& Köksel, H. (2001). Preliminary communication Dietary fiber content of bulgur as affected by wheat variety. Acta Alimentaria, 30(4), 407-414, doi:10.1556/AAlim.30.2001.4.9.

Qian, Y. Z., Chen, C., Zhang, Q., Li, Y., Chen, Z. J., \& Li, M. (2010). Concentrations of cadmium, lead, mercury and arsenic in Chinese market milled rice and associated population health risk. Food Control, 21(12), 1757-1763, doi:10.1016/j.foodcont.2010.08.005.

Rahman, M. A., \& Hasegawa, H. (2011). High levels of inorganic arsenic in rice in areas where arsenic-contaminated water is used for irrigation and cooking. Science of the Total Environment, 409(22), 4645-4655, doi:10.1016/j.scitotenv.2011.07.068.

RAIS (2016). Risk Assessment Information System, rais.ornl.gov Accessed April 2016.

Robson, T. C., Braungardt, C. B., Rieuwerts, J., \& Worsfold, P. (2014). Cadmium contamination of agricultural soils and crops resulting from sphalerite weathering. Environmental Pollution, 184, 283-289, doi:10.1016/j.envpol.2013.09.001.

Shi, G. L., Lou, L. Q., Zhang, S., Xia, X. W., \& Cai, Q. S. (2013). Arsenic, copper, and zinc contamination in soil and wheat during coal mining, with assessment of health risks for the inhabitants of Huaibei, China. Environmental Science and Pollution Research, 20(12), 8435-8445, doi:10.1007/s11356-013-1842-3.

Si, W., Liu, J., Cai, L., Jiang, H., Zheng, C., He, X., et al. (2015). Health Risks of Metals in Contaminated Farmland Soils and Spring Wheat Irrigated with Yellow River Water in Baotou, China. Bulletin of Environmental Contamination and Toxicology, 94(2), 214-219, doi:10.1007/s00128-014-1435-y.

Singh, A., Sharma, R. K., Agrawal, M., \& Marshall, F. M. (2010). Health risk assessment of heavy metals via dietary intake of foodstuffs from the wastewater irrigated site of a dry tropical area of India. Food and Chemical Toxicology, 48(2), 611-619, doi:10.1016/j.fct.2009.11.041.

Sofuoglu, S. C., Güzelkaya, H., Akgül, Ö., Kavcar, P., Kurucaovalı, F., \& Sofuoglu, A. (2014). Speciated arsenic concentrations, exposure, and associated health risks for rice and bulgur. Food and Chemical Toxicology, 64, 184-191, doi:10.1016/j.fct.2013.11.029.

Williams, P. N., Villada, A., Deacon, C., Raab, A., Figuerola, J., Green, A. J., et al. (2007). Greatly Enhanced Arsenic Shoot Assimilation in Rice Leads to Elevated Grain Levels Compared to Wheat and Barley. Environmental Science \& Technology, 41(19), 6854-6859, doi:10.1021/es070627i. 
Yeganeh, M., Afyuni, M., Khoshgoftarmanesh, A.-H., Soffianian, A.-R., \& Schulin, R. (2012). Health Risks of Metals in Soil, Water, and Major Food Crops in Hamedan Province, Iran. Human and Ecological Risk Assessment, 18(3), 547-568, doi:10.1080/10807039.2012.672886.

Yıldırım, A., Bayram, M., \& Öner, M.D. (2008). Bulgur milling using a helical disc mill. Journal of Food Engineering, 87, 564-570, doi: :10.1016/j.jfoodeng.2008.01.010.

Zeng, X., Wang, Z., Wang, J., Guo, J., Chen, X., \& Zhuang, J. (2015). Health risk assessment of heavy metals via dietary intake of wheat grown in Tianjin sewage irrigation area. Ecotoxicology, 24(10), 2115-2124, doi:10.1007/s10646-015-1547-0.

Zhu, P., Liang, X.-x., Wang, P., Wang, J., Gao, Y.-h., Hu, S.-g., et al. (2016). Assessment of dietary cadmium exposure: A cross-sectional study in rural areas of south China. Food Control, 62, 284-290, doi:10.1016/j.foodcont.2015.10.046.

Zhuang, P., McBride, M. B., Xia, H., Li, N., \& Li, Z. (2009). Health risk from heavy metals via consumption of food crops in the vicinity of Dabaoshan mine, South China. Science of the Total Environment, 407(5), 1551-1561, doi:10.1016/j.scitotenv.2008.10.061.

Table 1 The median and mean concentrations measured in this study and the "global" mean levels reported by (Adomako et al. 2011)

\begin{tabular}{lcccc}
\hline \multirow{2}{*}{ PTE } & \multicolumn{2}{c}{ Median - Mean in this study $(\mu \mathrm{g} / \mathrm{g})$} & \multicolumn{2}{c}{ Global Mean $(\mu \mathrm{g} / \mathrm{g})$} \\
& Rice & Bulgur & Rice & Wheat \\
\hline $\mathrm{Cd}$ & $0.012-0.232$ & $0.007-0.008$ & 0.020 & $\mathrm{NR}^{\mathrm{a}}$ \\
$\mathrm{Co}$ & $0.14-0.15$ & $0.017-0.016$ & 0.015 & $\mathrm{NR}$ \\
$\mathrm{Cu}$ & $1.64-1.71$ & $3.69-3.72$ & 2.2 & 6.1 \\
$\mathrm{Mn}$ & $6.8-6.9$ & $12.2-14.1$ & 10 & 38 \\
$\mathrm{~Pb}$ & $0.022-0.034$ & $0.014-0.023$ & 0.010 & $\mathrm{NR}$ \\
$\mathrm{Zn}$ & $11.9-12.0$ & $13.7-14.7$ & 13 & 23 \\
\hline
\end{tabular}

${ }^{\mathrm{a}}$ Not reported

Table 2 Descriptive statistics of individual ingestion exposure to PTE in rice and bulgur

\begin{tabular}{|c|c|c|c|c|c|c|c|c|c|c|c|c|}
\hline \multirow{2}{*}{$\begin{array}{l}\text { Exposure } \\
(\mu \mathrm{g} / \mathrm{kg}-\mathrm{d})\end{array}$} & \multicolumn{6}{|c|}{ Rice $(n=50)$} & \multicolumn{5}{|c|}{ Bulgur $(n=50)$} & \multirow[b]{2}{*}{$\operatorname{Max}^{\mathrm{d}}$} \\
\hline & $\operatorname{Min}^{a}$ & Median & Mean & $S D^{b}$ & $95^{\text {th }} p^{c}$ & $\operatorname{Max}^{d}$ & $\operatorname{Min}^{a}$ & Median & Mean & $S D^{b}$ & $95^{\text {th }} p^{c}$ & \\
\hline $\mathrm{Cd}$ & $<0.001$ & 0.02 & 0.37 & 0.77 & 1.54 & 4.10 & $<0.001$ & 0.005 & 0.009 & 0.02 & 0.02 & 0.14 \\
\hline Co & 0.026 & 0.23 & 0.24 & 0.13 & 0.47 & 0.49 & $<0.001$ & 0.011 & 0.018 & 0.03 & 0.04 & 0.21 \\
\hline $\mathrm{Pb}$ & $<0.001$ & 0.03 & 0.06 & 0.09 & 0.28 & 0.36 & $<0.001$ & 0.009 & 0.018 & 0.03 & 0.06 & 0.13 \\
\hline $\mathrm{Sr}$ & 0.02 & 0.13 & 0.16 & 0.11 & 0.35 & 0.46 & 0.13 & 1.17 & 2.31 & 3.71 & 11.5 & 19.7 \\
\hline $\mathrm{Cu}$ & 0.32 & 2.18 & 2.76 & 1.77 & 5.65 & 7.02 & 0.25 & 2.80 & 3.32 & 2.40 & 7.21 & 14.3 \\
\hline $\mathrm{Mn}$ & 1,57 & 11,2 & 9,4 & 7,0 & 23,1 & 29,6 & 0.78 & 10.3 & 12.7 & 11.2 & 34.6 & 66.3 \\
\hline $\mathrm{Zn}$ & 2.94 & 15.7 & 19.6 & 12.7 & 44.8 & 49.8 & 0.71 & 10.6 & 13.2 & 11.3 & 31.4 & 66.1 \\
\hline
\end{tabular}

${ }^{\mathrm{a}}$ Minimum, ${ }^{\mathrm{b}}$ Standard Deviation, ${ }^{\mathrm{c}}$ Percentile, ${ }^{\mathrm{d}}$ Maximum, 
Please cite as Sofuoglu SC and Sofuoglu A, 2017, Environ Geochem Health, doi: 10.1007/s10653-017-9954-1

Table 3 Individual chronic-toxic and carcinogenic risks associated with ingestion exposure to PTE in rice and bulgur $(n=50)$

\begin{tabular}{|c|c|c|c|c|c|c|c|c|}
\hline & \multicolumn{4}{|c|}{ Rice } & \multicolumn{4}{|c|}{ Bulgur } \\
\hline & Median & Mean & $95^{\text {th }}$ percentile & Maximum & Median & Mean & $95^{\text {th }}$ percentile & Maximum \\
\hline \multicolumn{9}{|c|}{ Chronic-Toxic Risk (HQ) } \\
\hline $\mathrm{Cd}$ & 0.02 & 0.37 & 1.49 & 4.11 & $<0.01$ & 0.01 & 0.02 & 0.14 \\
\hline Co & 0.76 & 0.80 & 1.60 & 1.64 & 0.04 & 0.06 & 0.13 & 0.70 \\
\hline $\mathrm{Cu}$ & 0.05 & 0.07 & 0.14 & 0.18 & 0.07 & 0.08 & 0.18 & 0.35 \\
\hline $\mathrm{Mn}$ & 0.07 & 0.08 & 0.16 & 0.21 & 0.07 & 0.09 & 0.25 & 0.47 \\
\hline $\mathrm{Sr}$ & $<0.01$ & $<0.01$ & $<0.01$ & $<0.01$ & $<0.01$ & $<0.01$ & 0.02 & 0.03 \\
\hline $\mathrm{Zn}$ & 0.05 & 0.07 & 0.16 & 0.17 & 0.04 & 0.04 & 0.10 & 0.22 \\
\hline \multicolumn{9}{|c|}{ Carcinogenic Risk (R) } \\
\hline $\mathrm{Pb}$ & $2.67 \times 10^{-7}$ & $5.36 \times 10^{-7}$ & $2.42 \times 10^{-6}$ & $3.02 \times 10^{-6}$ & $7.82 \times 10^{-8}$ & $1.57 \times 10^{-7}$ & $5.28 \times 10^{-7}$ & $1.10 \times 10^{-6}$ \\
\hline
\end{tabular}

Table 4 Uncertainty in the probabilistic estimations of $50^{\text {th }}$ and $95^{\text {th }}$ percentile risks

\begin{tabular}{|c|c|c|c|c|c|c|c|c|c|}
\hline & \multirow[b]{2}{*}{ Percentile } & \multicolumn{4}{|c|}{ Rice } & \multicolumn{4}{|c|}{ Bulgur } \\
\hline & & $5^{\text {th }}$ & $50^{\text {th }}$ & $95^{\text {th }}$ & $\operatorname{CoD}^{a}$ & $5^{\text {th }}$ & $50^{\text {th }}$ & $95^{\text {th }}$ & CoD \\
\hline \multirow{2}{*}{$\mathrm{Cd}-\mathrm{HQ}^{\mathrm{b}}$} & $50^{\text {th }}$ & 0.056 & 0.072 & 0.100 & 61 & 0.042 & 0.049 & 0.062 & 41 \\
\hline & $95^{\text {th }}$ & 1.622 & 1.806 & 2.309 & 38 & 1.326 & 1.554 & 2.801 & 95 \\
\hline \multirow{2}{*}{$\mathrm{Co}-\mathrm{HQ}$} & $50^{\text {th }}$ & 0.612 & 0.642 & 0.672 & 9 & 0.036 & 0.039 & 0.041 & 13 \\
\hline & $95^{\text {th }}$ & 1.617 & 1.676 & 1.797 & 11 & 0.148 & 0.156 & 0.164 & 10 \\
\hline \multirow{2}{*}{$\mathrm{Cu}-\mathrm{HQ}$} & $50^{\text {th }}$ & 0.053 & 0.055 & 0.058 & 9 & 0.050 & 0.052 & 0.055 & 10 \\
\hline & $95^{\text {th }}$ & 0.144 & 0.156 & 0.166 & 14 & 0.140 & 0.154 & 0.167 & 18 \\
\hline \multirow{2}{*}{$\mathrm{Mn}-\mathrm{HQ}$} & $50^{\text {th }}$ & 0.062 & 0.065 & 0.068 & 9 & 0.067 & 0.072 & 0.075 & 11 \\
\hline & $95^{\text {th }}$ & 0.161 & 0.168 & 0.183 & 13 & 0.203 & 0.223 & 0.241 & 17 \\
\hline \multirow{2}{*}{$\mathrm{Sr}-\mathrm{HQ}$} & $50^{\text {th }}$ & $2.0 \times 10^{-4}$ & $2.1 \times 10^{-4}$ & $2.2 \times 10^{-4}$ & 10 & $2.0 \times 10^{-3}$ & $2.1 \times 10^{-3}$ & $2.2 \times 10^{-3}$ & 10 \\
\hline & $95^{\text {th }}$ & $5.9 \times 10^{-4}$ & $6.4 \times 10^{-4}$ & $6.9 \times 10^{-4}$ & 16 & $8.6 \times 10^{-3}$ & $9.8 \times 10^{-3}$ & $1.1 \times 10^{-2}$ & 24 \\
\hline \multirow{2}{*}{$\mathrm{Zn}-\mathrm{HQ}$} & $50^{\text {th }}$ & 0.048 & 0.050 & 0.052 & 8 & 0.031 & 0.033 & 0.035 & 12 \\
\hline & $95^{\text {th }}$ & 0.119 & 0.125 & 0.132 & 10 & 0.096 & 0.102 & 0.109 & 13 \\
\hline \multirow{2}{*}{$P b-R^{c}$} & $50^{\text {th }}$ & $2.2 \times 10^{-7}$ & $2.4 \times 10^{-7}$ & $2.6 \times 10^{-7}$ & 17 & $5.1 \times 10^{-8}$ & $5.8 \times 10^{-8}$ & $6.3 \times 10^{-8}$ & 21 \\
\hline & $95^{\text {th }}$ & $1.4 \times 10^{-6}$ & $1.6 \times 10^{-6}$ & $1.8 \times 10^{-6}$ & 25 & $7.6 \times 10^{-7}$ & $9.0 \times 10^{-7}$ & $1.1 \times 10^{-6}$ & 38 \\
\hline
\end{tabular}

${ }^{\mathrm{a}} \mathrm{CoD}$ : Coefficient of Dispersion (\%)

${ }^{b}$ HQ: Hazard Quotient for Chronic-Toxic Risk

${ }^{\mathrm{c}} \mathrm{R}$ : Lifetime Excess Carcinogenic Risk 


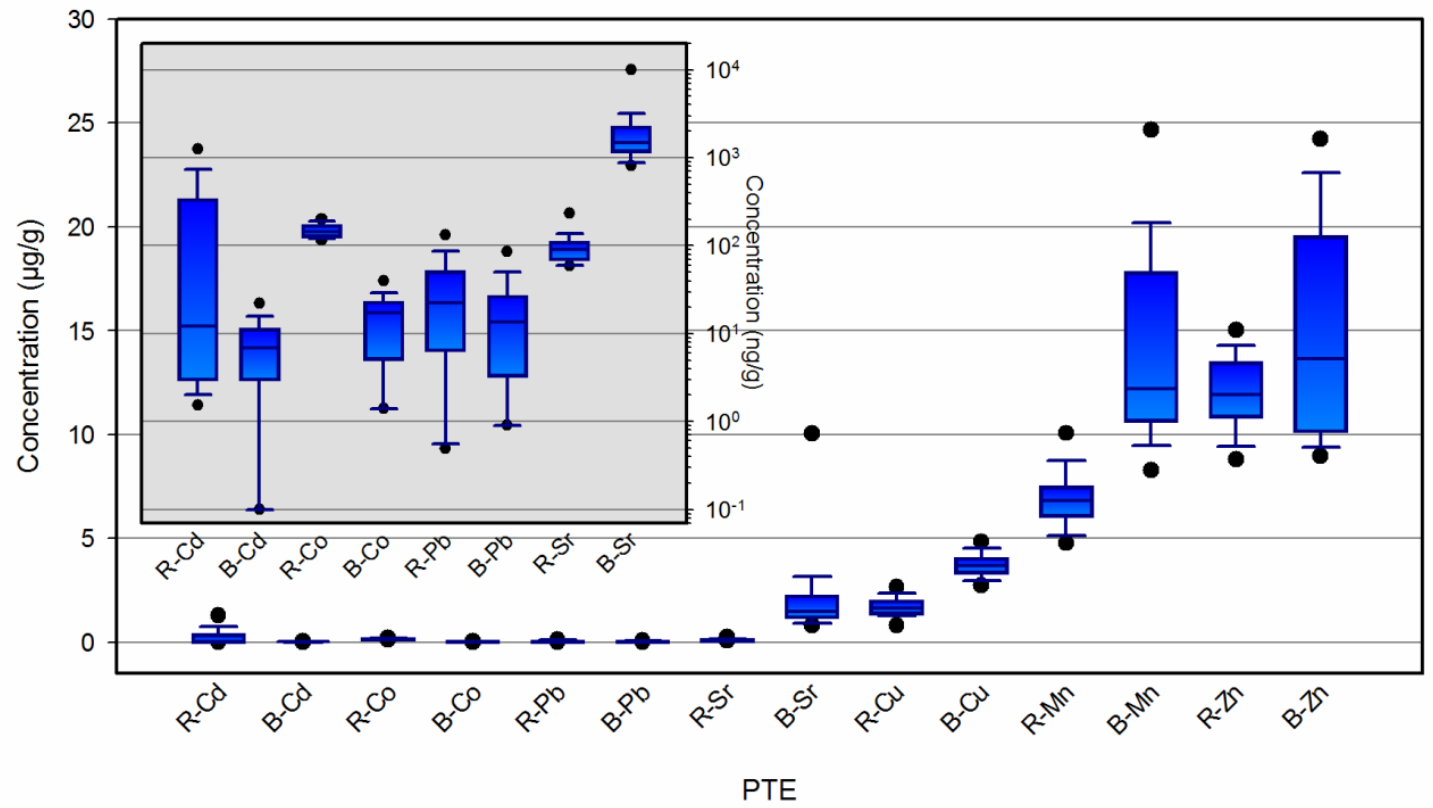

Fig 1 Concentrations of Potentially Toxic Elements (PTE) in Rice (R) and Bulgur (B) (Wet weight, black dots depict $5^{\text {th }}$ and $95^{\text {th }}$ percentiles)

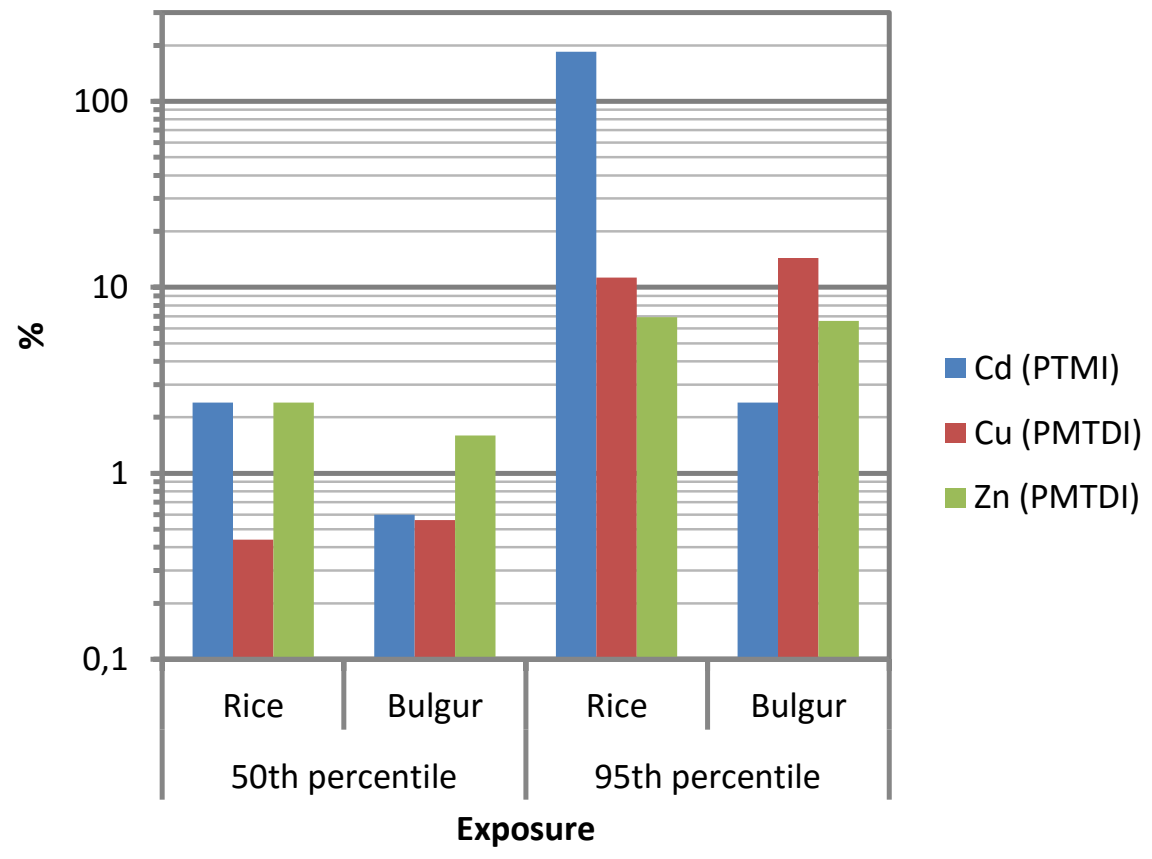

Fig 2 Comparison of exposure with tolerable intake levels (PTMI: provisional tolerable monthly intake, PMTDI: provisional maximum tolerable daily intake) 


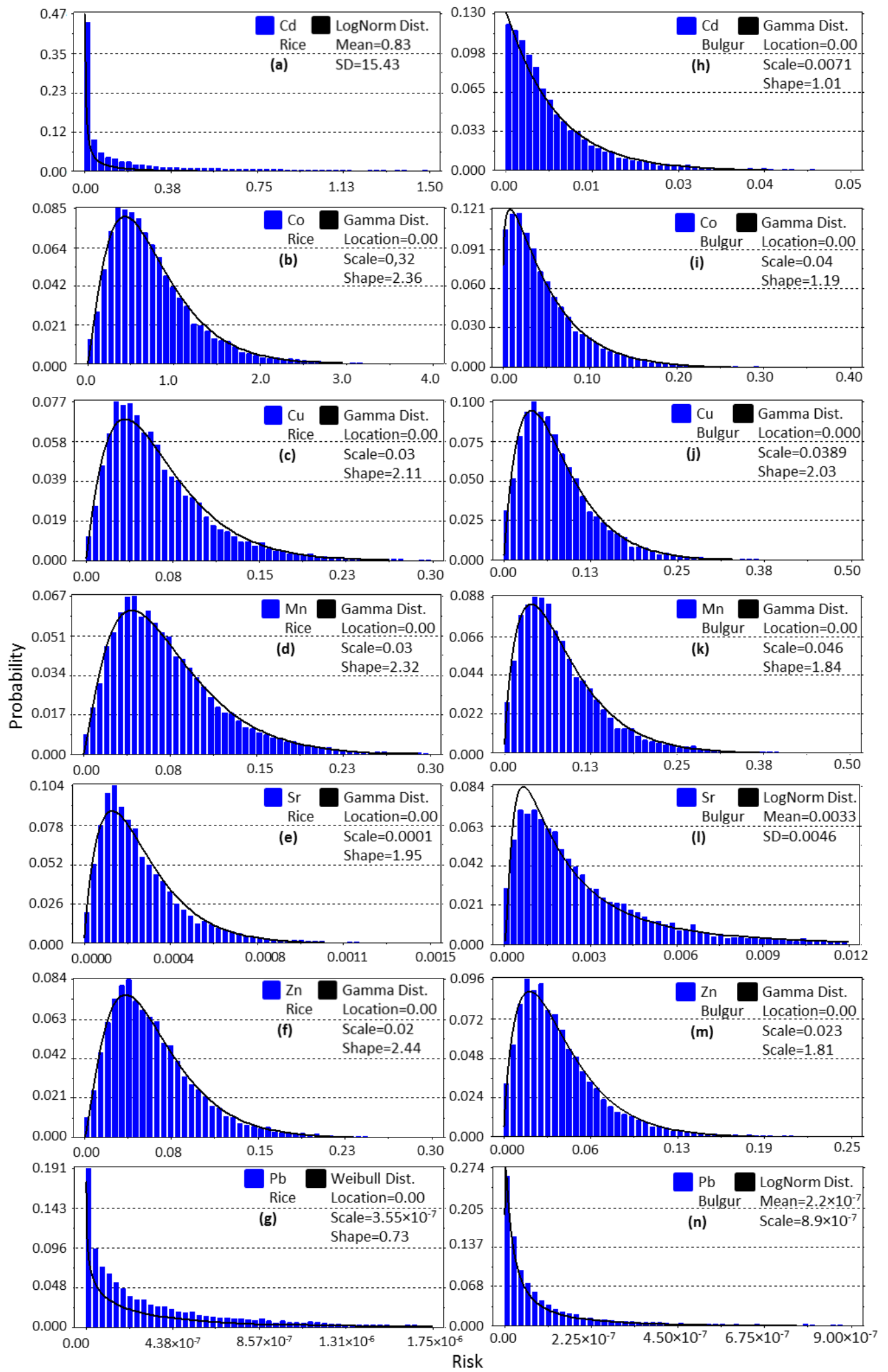

Fig 3 Distributions of risk associated with ingestion exposure to PTE in rice $(a, b, c, d, e, f, g)$ and bulgur (h,i,j, $, \mathrm{l}, \mathrm{l}, \mathrm{m}, \mathrm{n})$ for $\mathrm{Cd}, \mathrm{Co}, \mathrm{Cu}, \mathrm{Mn}, \mathrm{Sr}, \mathrm{Zn}$ chronic-toxic and $\mathrm{Pb}$ carcinogenic risk 